\title{
Does normal pulse rate correlate with watching horror movies?
}

\begin{abstract}
The objective of present study was to correlate normal pulse rate with watching horror movies. Total of 200 subjects participated in this study. Pulse rate was measured by using a simple method because there is not available a scientific method. We simply examined their pulse rate by keeping index and third fingers on the neck to the side of the trachea, at the wrist between the bone and the tendon over outward artery. When we felt a pulse, we started counting number of beats in 10 seconds. To estimate pulse rate, we multiplied this number with 6 . A questionnaire was formulated to correlate normal pulse rate with watching horror movies. We asked some questions and wrote their answers. It was concluded that students with elevated pulse rate had no fear to horror movies while with lower pulse rate; students had fear to horror movies.
\end{abstract}

Volume 12 Issue 2 - 2019

\author{
Muhammad Imran Qadir, Muhammad Asif \\ Institute of Molecular Biology and Biotechnology, Baha Uddin \\ Zakariya University, Multan, Pakistan
}

Correspondence: Muhammad Asif, Institute of Molecular Biology and Biotechnology, Baha Uddin Zakariya University, Multan, Pakistan,Email asiflang786@gmail.com

Received: February 19, 2019 | Published: March 28, 2019

Keywords: horror movies, pulse rate, heart attack, BPM, tendon, trachea

\section{Introduction}

Pulse rate is also identified as heart rate or heartbeat. It is the number of times one's heart pumps in a minute. Normal rate of pulse differs among population but an average range for adults is 60-100. A normal rate depends upon the individual's age, body size, heart state, medication and even outside temperature. Emotions can alter heart rate, for example, feeling excited or scared can uplift the rate. The speed of heart gradually decreases when a person grows from child to adult. Heartbeat is also lower in resting state than excited condition. It increases while we do some physical activities, to meet the high supply of oxygen and necessary nutrients. A little exercise may rise your heart's health and its aerobic capacity. It also helps in improving memory and reasoning. It lowers the risk of heart attack. By checking the pulse rate, we can determine how well our heart is operational as well as our general health and fitness. Active people usually have softer heart speed as their heart muscle is in healthier condition and does not require working hard to uphold regular beat. An irregular pulse can even lead to death. One in every four deaths in the United States happens as a consequence of heart disease. Observing your heart rate can comfort the heart complications.

There is a key relation between watching horror movies and pulse rate. ${ }^{1,2}$ Many types of scary movies are available on internet which can trigger an emergency response. When you feel fear after watching such videos, your mind takes it as stimulus and release adrenalin hormone. It prepares the body to maintain nervousness and boosts your body temperature, heartbeat and blood pressure. You feel anxiety and stress which can direct to physical effects such as increased heart rate and sweating. In this case, heartbeat may divert from normal (60100 ) to $90-160$ BPM (Beats per Minute) as someone is doing light exercise. The objective of present study was to correlate normal pulse rate with watching horror movies.

\section{Materials and method}

Total of 200 subjects participated in this study. There is no scientific method available at medical level. So, we used a very simple method. We simply checked their pulse rate by employing index and third fingers on the neck to the adjacent of the trachea, at the wrist between the bone and the tendon over outward artery. When we felt a pulse, we began counting number of beats in 10 seconds. To calculate pulse rate, we multiplied this number with 6 . In this way, we designed the subjects' pulse rate. A questionnaire was prepared to correlate normal pulse rate with watching horror movies. We asked questions and their answers.

\section{Statistical analysis}

It was done by using MS EXCEL software. $t$-test was used to analyze the result. $p<0.05$ was considered as significant.

\section{Results and discussion (Table I-3)}

From the above Table 1, there is less $\mathrm{P}$ value calculated than the given $\mathrm{P}$ value. So, it shows that there is a significant relation between normal pulse rate and watching horror movies. From Table 2, the majority of the male love watching horror movies while a smaller number of male's hate watching such movies. The $p$ value $(0.004)$ calculated is less than the original $p$ value. So, there is a significant relation between higher pulse rate and watching horror movies in male subjects. Table 3 explains that mostly females hate watching horror movies. The $p$ value evaluated is greater than the assumed $p$ value. In this situation, there is no significant relation between higher pulse rate and watching horror movies. In case of fever and disease, pulse rate increases. The reason is that pathogens attack on blood cells. That's why our immune system produces antibodies against these microbes and there is an increase in blood circulation around the body. Hence, temperature and pulse rate is boosted. ${ }^{3-8}$

Table I Relation of fluctuating pulse rate with watching horror movies in both males and females

\begin{tabular}{ll}
\hline Loving horror movies & Hating horror movies \\
\hline $8 \mathrm{I} .47 \pm \mid 2.94$ & $79.46 \pm \mid \mathrm{I} .8 \mathrm{I}$ \\
\hline
\end{tabular}

$P=0.03(P<0.05$ was considered as standard $)$

Table 2 Relation of varying pulse rate with watching horror movies in males

\begin{tabular}{ll}
\hline Liking horror movies & Disliking horror movies \\
\hline $87.82 \pm 15.78$ & $79.07 \pm 8.84$
\end{tabular}

$\mathrm{P}=0.004$ ( $\mathrm{P}<0.05$ considered as significant $)$

Table 3 Relation of changing pulse rate with watching horror movies in females

\begin{tabular}{ll}
\hline Liking horror movies & Disliking horror movies \\
\hline $77.83 \pm 12.63$ & $79 \pm 12.40$
\end{tabular}

$P=0.63(P<0.05$ considered as significant $)$ 


\section{Conclusion}

It was concluded that students with higher pulse rate had no fear to horror movies while with lower pulse rate; students had fear to horror movies.

\section{Acknowledgments}

None.

\section{Conflicts of interest}

Authors declare that there is no conflict of interest.

\section{References}

1. Aly B, Eversten F, Omoba O, et al. Effects of Auditory Stimuli on Blood Pressure, Respiration Rate, and Heart Rate Changes While Watching a Suspenseful Video. J Hypertens. 2017;17(12 Pt 2):1893-1897.
2. Ivarsson $\mathrm{M}$, Anderson $\mathrm{M}$, Åkerstedt $\mathrm{T}$, et al. Playing a violent television game affects heart rate variability. Acta paediatrica. 2009;98(1):166-172.

3. Qadir MI, Javid A. Awareness about Crohn's Disease in biotechnology students. Glo Adv Res J Med Medical Sci. 2018;7(3):062-064.

4. Qadir MI, Saleem A. Awareness about ischemic heart disease in university biotechnology students. Glo Adv Res J Med Medical Sci. 2018;7(3):059-061.

5. Qadir MI, Ishfaq S. Awareness about hypertension in biology students. Int J Mod Pharma Res. 2018;7(2):08-10.

6. Qadir MI, Mehwish. Awareness about psoriasis disease. Int J Mod Pharma Res. 2018;7(2):17-18.

7. Qadir MI, Shahzad R. Awareness about obesity in postgraduate students of biotechnology. Int J Mod Pharma Res. 2018;7(2):14-16.

8. Qadir MI, Rizvi M. Awareness about thalassemia in post graduate students. MOJ Lymphology \& Phlebology. 2018;2(1):14-16. 